\title{
The relationship between interfragmentary movement and cell differentiation in early fracture healing under locking plate fixation
}

(1)

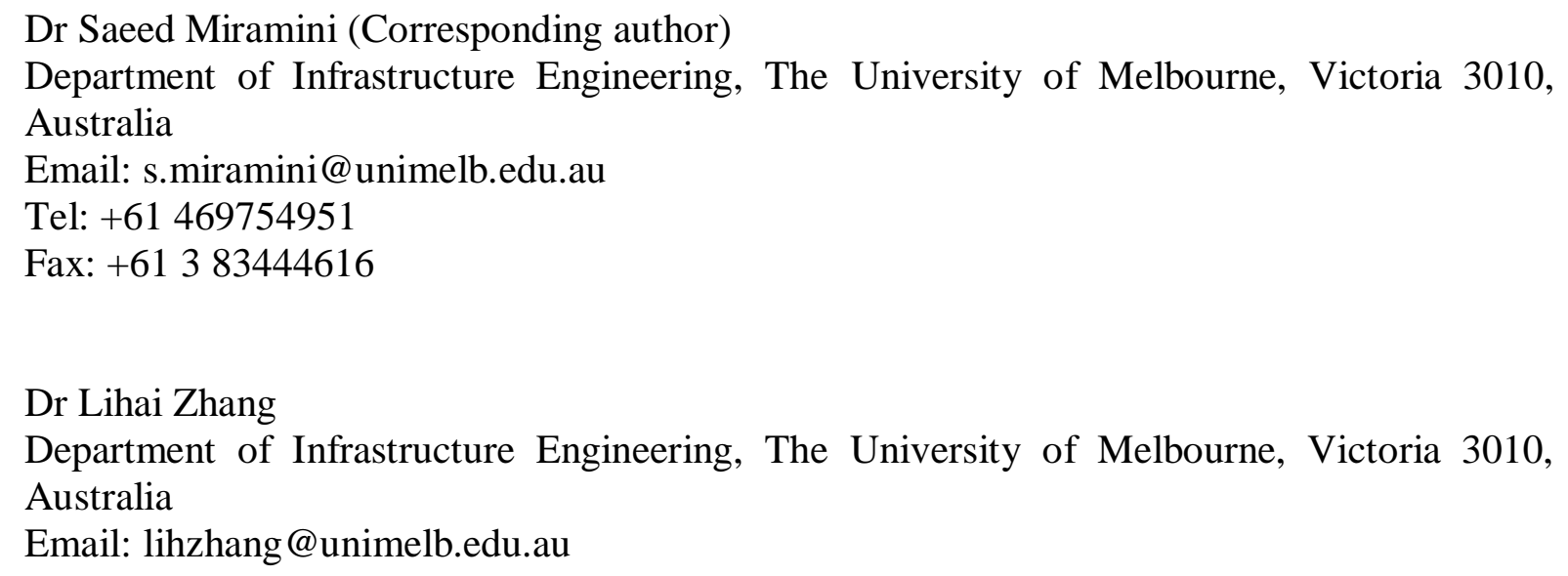




\section{ABSTRACT}

43

44 Interfragmentary movement (IFM) at the fracture site plays an important role in fracture healing, particularly during its early stage, via influencing the mechanical microenvironment of mesenchymal stem cells within the fracture callus. However, the effect of changes in IFM resulting from the changes in the configuration of locking plate fixation on cell differentiation has not yet been fully understood.

In this study, mechanical experiments on surrogate tibia specimens, manufactured from specially formulated polyurethane, were conducted to investigate changes in IFM of fractures under various locking plate fixation configurations and loading magnitudes. The effect of the observed IFM on callus cell differentiation was then further studied using computational simulation.

We found that during the early stage, cell differentiation in the fracture callus is highly influenced by fracture gap size and IFM, which in turn, is highly sensitive to locking plate fixation configuration. The computational model predicted that a small gap size (e.g. $1 \mathrm{~mm})$ under a relatively flexible configuration of locking plate fixation (larger bone-plate distances and working lengths) could experience excessive strain and fluid flow within the fracture site, resulting in excessive fibrous tissue differentiation and delayed healing. By contrast, a relatively flexible configuration of locking plate fixation was predicted to improve cartilaginous callus formation and bone healing for a relatively larger gap size (e.g. 3mm).

If further confirmed by animal and human studies, the research outcome of this paper may have implications for orthopaedic surgeons in optimising the application of locking plate fixations for fractures in clinical practice.

Keywords: Fracture healing; Mesenchymal stem cell differentiation; Locking plate fixation; Mechanical testing; Computational simulation; Osteoporosis 


\section{INTRODUCTION}

Bone fractures, particularly those associated with osteoporosis, have become one of the most prevalent trauma conditions seen daily in clinical practice in an era of demographic ageing. The costs and impairment in quality of life resulting from fractures are significant. The success of fracture repair is heavily dependent on the balance between stability and biology at the fracture site. However, current fracture fixation strategies mainly focus on stability at the expense of biology, leading to a situation in which the optimal balance between stability and biology remains poorly understood [1].

Interfragmentary movement (IFM) and geometry of the fracture site both significantly influence fracture healing [2-5]. The degree of IFM depends on the type and stiffness of the fracture fixation and the mechanical loading applied to the fracture. While rigid fixation suppresses the IFM and results in insufficient callus formation and delayed healing, a relatively flexible fixation can provide a certain degree of IFM that encourages callus formation [6]. However too much flexibility may result in unstable fixation, leading to excessive IFM and delayed fracture healing [2,5]. This suggests that there should be an optimal balance between stability and biology. In addition, fracture gap size is another important factor that influences the healing process [7]. For a given IFM, the fracture callus between a small fracture gap size generally experiences a larger stress and strain compared with that between a relatively large gap size $[8,9]$.

IFM is largely controlled by the configuration of fixation devices. Recently, the application of locking plate fixation has become increasing popular in surgical treatment of fractures [10]. In contrast to the conventional compression plate, the locking plate fixation aims to provide the fracture site with a certain degree of IFM that is essential for indirect healing, [11]. In addition, locking plate fixation stabilizes the fracture by means of locking screws, eliminating the necessity of contact between bone and plate, thereby preserving 
periosteal blood supply beneath the plate [12]. The locking plate fixations can be suitable for number of fractures including complex periarticular fractures, comminuted metaphyseal or diaphyseal fractures, osteoporotic fractures as well as fracture mal-union and pathological bones. Locking plate fixations can also be a good option for metaphyseal fractures of long bone in which the intramedullary nailing has a high risk of misalignment $[13,14,12]$. However, there are several studies suggesting that the locking plate fixations are not flexible enough to reliably promote indirect healing $[1,15,16,9]$. In addition, IFM induced by locking plate fixation is not uniform across the fracture gap [i.e. IFM is much smaller at the near cortex (cortex adjacent to plate) compared with the far cortex], and so results in asymmetric and inconsistent tissue formation, which is unfavourable to fracture healing [16].

In this study, we conducted a series of mechanical experiments involving surrogate tibia specimens and locking plate fixations to investigate the characteristics of IFM at fracture site under various locking plate fixation configurations. The effect of experimentally observed IFM on the mesenchymal stem cell differentiation pattern in the early stage of healing was then investigated using our recently developed computational model of fracture healing [17], which has the capability of linking changes in the configuration of the fixation system to changes in cellular mechanical microenvironments, and ultimately the mesenchymal stem cell differentiation pattern in the early stage of fracture healing.

\section{MATERIAL AND METHODS}

As illustrated in Fig.1, firstly, an experimental protocol was presented to measure the IFM at the near and far cortex of a transverse fracture under different configurations of locking plate fixation [i.e. namely the Bone-Plate Distance (BPD) and the plate Working Length (WL)]. Secondly, the actual geometry of the fractured surrogate tibia specimens under locking plate fixation was imported into our developed computational model of fracture 
healing $[18,19,17]$ using $\mathrm{CT}$ scan imaging and 3D model reconstruction techniques to investigate the effect of the changes in the configuration of the fixation system on the cellular mechanical microenvironments, and ultimately cell differentiation pattern in the early stage of healing. This research focused on the early stage of bone healing (i.e. first week after surgical operation) as studies have suggested that the mechanical conditions at the fracture site in this stage is particularly of critical importance to the entire healing process [20-25]. At this stage, mesenchymal stem cells in the fracture callus commit to chondrogenic or osteogenic fate [22], and are therefore especially sensitive to their mechanical microenvironment [21].

\subsection{Mechanical testing of surrogate bone specimens}

\section{Surrogate bone specimens}

Twenty surrogates of tibial bone specimens manufactured by Synbone (Malans, Switzerland) were used for mechanical testing. The purpose of using surrogate bone tibia instead of cadaver specimens was to eliminate inter-specimen variability in the analysis of the influence of BPD and WL on the fracture IFM. As shown in Table 1, the twenty surrogates were divided into four groups (five specimens in each group) with different LCP configurations in each group. The surrogates, $387 \mathrm{~mm}$ long with $27 \mathrm{~mm}$ shaft diameter, were manufactured from specially formulated polyurethane foam comprising an inner cancellous bone and an outer shell of cortical bone, replicating the geometrical and mechanical properties of real adult human tibia (compressive Young's modulus was around $1500 \mathrm{MPa}$ ). The use of surrogates could eliminate the effect of bone model sample variability in this study. 

with locking screws (Oberdorf,, Switzerland) were used in this study. The plates were 206 $\mathrm{mm}$ long, $17.5 \mathrm{~mm}$ wide and $5.2 \mathrm{~mm}$ thick with 11 holes, while the locking screws were 40 $\mathrm{mm}$ long with $4.5 \mathrm{~mm}$ core diameter. Both the plates and the screws were manufactured from surgical grade stainless steel. The LCPs were applied medially on the tibia diaphysis surrogates to stabilize an induced transverse osteotomy. All the screws were tightened to 4 $\mathrm{Nm}$ and the BPD was adjusted by temporary spacers during the specimen preparation. After applying the LCP on the surrogates, a transverse fracture gap was created in front of the central hole of the plate. A transverse fracture gap was investigated in this study as it is one of the most common types of shaft fractures adopted in animal models $[3,26,4]$. As illustrated in

Table 1, four configuration groups of locking plate fixation were studied to explore the effect of both BPD and WL on the IFM at the near and far cortex of the fracture site. To compare the different configurations of locking plate fixation, the standard osteotomy model [27] with the screws placed in the first, third and fifth holes from the fracture site and BPD of $2 \mathrm{~mm}$ was considered as a control model.

Mechanical testing protocol

The fracture models were tested under axial compression with a material testing system (Instron 5569A; Instron, Canton, Massachusetts). The distal end of the tibia surrogate specimens were rigidly fixed by a lathe chuck and the axial compressive load was applied on the tibia intercondylar eminence to allow free rotation (Fig.2.a). This set-up simulates the physiological loading conditions applied on tibia through knee and ankle [28,29]. Four configuration groups of five specimens were tested and a quasi-static axial compressive load of 100,150 and $200 \mathrm{~N}$ was applied to the specimens respectively. These loading conditions 
represent the allowable partial weight bearing following surgical operation [30]. The magnitude of IFM at the near and far cortex of the fracture was measured by two digital callipers with $0.01 \mathrm{~mm}$ resolution (Kincrome, Victoria, Australia).

\section{Statistical analysis}

For each level of applied load, the IFM at the near and far cortex of the four experimental groups were cross-compared using $t$-test to detect any significant differences. Our power calculations demonstrated that five tibia surrogate specimens in each sub-group would be able to achieve a significance level of 0.05 with a power of $98 \%$. The statistical analysis was performed using MATLAB (R2010, The MathWorks, Inc., Natick, MA, USA).

\subsection{Computational modelling of early stage fracture healing}

Our recently developed computational model of fracture healing [17] was used to investigate the influence of the change of IFM (measured at Section 2.1) resulting from the change of fixation configuration, on the cellular mechanical microenvironment and ultimately cell differentiation pattern during the early stage of healing. As shown in Fig.2.b, the 3D geometry of the bone fracture model used in the computational analysis consisted of a fractured tibia specimen with different gap sizes (i.e. $1 \mathrm{~mm}$ and $3 \mathrm{~mm}$ ), locking plate fixation with various configurations (i.e. $\mathrm{BPD}=0,2,4 \mathrm{~mm}$ and $\mathrm{WL}=30,65,100 \mathrm{~mm}$ ) and a soft fracture callus. The construction of a complete 3D geometry of bone fracture model involved the following steps:

Step 1: The 2D CT scan images of the surrogate tibia used in the mechanical testing were obtained by using a CT scanner (Siemens definition flash dual source dual energy) at Epworth Richmond Hospital (Richmond, Victoria, Australia) with 0.6 pitch number and 0.7 $\mathrm{mm}$ resolution. The effective slice spacing (resolution) of $0.7 \mathrm{~mm}$ to $1 \mathrm{~mm}$ is commonly 
applied for CT scan images acquisition required for 3D geometry reconstruction of macroscopic tissues such as bone [31,32], since it can result in high quality 3D geometry without leading to computational instability. Applying higher resolutions can result in creation of unsmooth surfaces leading to unnecessary small mesh sizes resulting in computational instability in the finite element model [33].

Step 2: The 3D geometry of the tibia was reconstructed from the CT scan images by using commercial medical image processing software Mimics 14.11 (Materialise, Haasrode, Belgium) [34].

Step 3: The 3D geometry of locking plate fixations used in the mechanical testing was reconstructed and applied on the tibia model created in Step 2 by using commercial CAD software Solidworks (Dassault Systemes, MA, USA). In addition, a $1 \mathrm{~mm}$ and $3 \mathrm{~mm}$ transverse fracture gap were applied in the 3D model to investigate the effect of different gap sizes on the mechanical microenvironment of the fractures. A 3D fracture callus was also created at the fracture site by assuming a callus index of 1.1 (i.e. the callus diameter divided by bone diameter). The callus index of 1.1 was selected following the study of Horn et al. [35] who measured the callus size of a group of patients with tibial fracture stabilized by locking plates.

Step 4: Finally, the complete 3D geometry of bone fracture model constructed in Step 3 was imported into our previously developed computational model [17] for numerical analysis.

The fracture callus was modelled using the Theory of Porous Media [36-38] which is commonly used to simulate the mechanical behaviour of soft biological tissues (e.g. cartilage) [38-40]. In addition to the fracture callus, bone marrow and cortical bone were also modelled as a poroelastic tissue [41]. The material properties of the tissues applied in the computational model are presented in Table 2. The external boundaries of all the tissues, i.e. the fracture 
callus, cortical bone and marrow, were assumed to be impermeable to fluid flow [41]. The interface between the screw and the bone was defined fully bonded in the finite element model.

The cortical bone, marrow and callus were meshed with 11446, 6115 and 2595 second-order tetrahedral elements respectively (Fig.2.c). The relative tolerance of $10^{-4} \mathrm{~m}$ for displacement and $10 \mathrm{~Pa}$ for pressure was applied in the solver. The values of tolerances and mesh sizes were obtained by a convergence analysis when the difference between current and subsequent solutions was less than $2 \%$. The total Lagrange formulation with material coordinate system was applied in the model to account for large strains.

To replicate the experiment, the protocol used in the mechanical testing was adopted in the computational model. The distal part of the tibia was fixed in the model and the proximal part was subjected to 100,150 and $200 \mathrm{~N}$ axial compressive ramp load in $0.5 \mathrm{~s}$. The IFM at the near and far cortex was numerically calculated and compared with results of the mechanical testing. It is reasonable to assume that the IFM measured in the experiments is approximately equal to in vivo IFM in the early stages of callus formation when callus is composed of granulation tissue. After reproducing the mechanical testing results, the mechanical microenvironment of early fracture callus (i.e. octahedral shear strain and fluid flow) was calculated and finally the initial cell differentiation was predicted.

\section{RESULTS AND DISCUSSION}

Fig.3 illustrates the IFM at the near and far cortex of the four configuration groups obtained in the mechanical testing. For all the four configurations under external loading from $100-200 \mathrm{~N}$, it can be seen that IFM is much smaller at the near cortex in comparison with that at the far cortex $(p<0.001)$. For example, as shown in Fig.3a, for control model $(\mathrm{C} 1)$ and $100 \mathrm{~N}$ applied loading, IFM at the far cortex is more than four times larger than that at 
the near cortex. The small IFM at the near cortex of the fractures stabilized by rigid configurations of locking plate fixation could potentially result in delayed healing [9]

In addition, the non-uniform gap motion (i.e. the different IFM at the near and far cortex) can result in asymmetric and inconsistent callus formation which is unfavourable for healing [16]. In order to quantify and compare the uniformity of IFM between the fractures under different fixation configurations, the ratio of IFM at the far cortex $\left(\mathrm{IFM}_{\mathrm{FC}}\right)$ to IFM at the near cortex $\left(\mathrm{IFM}_{\mathrm{NC}}\right)$ is illustrated in Fig.4. A smaller ratio of $\mathrm{IFM}_{\mathrm{FC}} / \mathrm{IFM}_{\mathrm{NC}}$ indicates that the IFM is more uniform across the fracture gap. The mechanical testing results show that the increase of BPD and WL in combination with axial loading magnitude could not only increase the IFM at both the near and far cortex (Fig.3, Table 3) but also decrease their difference (Fig.4, Table 4), resulting in a more uniform IFM.

The results show that the increase of BPD alone $(C 2,100 N)$ could increase IFM at the near cortex by $46 \%(p<0.05)$ and the increase of WL alone $(\mathrm{C} 3,100 \mathrm{~N})$ increases the IFM by $130 \%(p<0.05)$. Furthermore, simultaneous increase of BPD and WL (i.e. C4, 100N) has a collective effect, resulting in $218 \%$ increase in IFM at the near cortex $(p<0.05)$. Most importantly, the increase becomes more significant when the external loading is high $(\mathrm{C} 4$, $200 \mathrm{~N})$, i.e. increasing IFM at the near cortex by $668 \%$ and decreasing the ratio of $\mathrm{IFM}_{\mathrm{FC}} / \mathrm{IFM}_{\mathrm{NC}}$ by $25 \%$ at the same time $(p<0.05)$.

The mechanical testing results from our study suggest that the adjustment of the configuration of internal fixation (e.g. BPD and WL) in conjunction with the magnitude of loading could alter the IFM distribution at fracture site. The influence of the IFM distribution on the mesenchymal stem cell differentiation pattern within the fracture callus was further investigated using the developed computational model. Although the fracture callus was not included in the mechanical experiments, it can be reasonably assumed that the IFM observed 
in the experiments is approximately equal to the IFM of the fracture during the early stage when the callus is composed of granulation tissue with very low stiffness. Fig.5.a compares the IFM at the near cortex and far cortex between the mechanical testing measurements and computational model predictions for control group (C1). It can be seen that the numerical results fit the experimental data very well, with normalized root-mean-square deviation (NRMSD) of $2.8 \%$ and $4.2 \%$ for near cortex and far cortex respectively.

After validation of the computational model prediction of IFM against the mechanical experiment results, the model was employed to investigate the effect of flexibility of locking plate fixation on bone healing. The model simulated the early stage of bone healing based on mechanoregulation theory proposed by Prendergast, et al. [42,43]. According to this mechanoregulation theory, cell differentiation within the callus is modulated by two mechanical stimuli [i.e. octahedral shear strain of the tissue $(\gamma)$ and interstitial fluid flow (v)], and has been shown to have the most accurate prediction of cell differentiation among the proposed theories [44]. This theory predicts cell differentiation pattern based on mechanical stimuli index " $S$ " $(S=\gamma / a+v / b ; a=0.0375$ and $b=3 \mu \mathrm{m} / \mathrm{s})$. A high magnitude of mechanical stimuli in the early stage $(S>3)$ results in fibroblast differentiation. An intermediate $S(1<\mathrm{S} \leq 3)$ favours chondroblast differentiation, and low mechanical stimuli $\mathrm{S} \leq 1$ leads to osteoblast differentiation. Fig.5.b illustrates the computational model prediction of early-stage cell differentiation at transverse cross-section of the callus (i.e. section A-A indicated in Fig.2.b) for C1, 150N, gap size $=3 \mathrm{~mm}$. It demonstrates that the developed model could predict the spatial dependency of cell differentiation across the fracture gap. Fig.6 illustrates the computational model prediction of the mechanical stimuli index (S) and dominant cell differentiation at the near and far cortex of the fractures stabilized by different configurations of the locking plate fixation under physiological loading conditions post- 
surgery. It can be seen that the magnitude of $S$ as well as the callus cell differentiation are highly dependent on both the fracture gap size and the flexibility of locking plate fixation.

Locking plate fixation aims at indirect fracture healing with callus formation $[16,14]$. Therefore, during the early stage of healing, chondroblast differentiation in the fracture site is favourable as it results in cartilaginous callus formation and subsequently indirect healing in the next stages [45]. In addition, the differentiation of osteoblasts in the fracture gap under the locking plates might not result in direct osteonal bone union (i.e. direct healing) $[45,9,46]$, as this requires the degree of interfragmentary motion to be kept as low as possible during the period of fracture healing, and this can only reliably be achieved by interfragmentary compression and using a rigid fixation system (i.e. compression plating). Further, the study of Mckibbin [47] showed that direct osteonal bone union is an extremely slow and mechanically inferior healing process involving cortical bone remodelling. Thus, under locking plate fixations, the early-stage differentiation of osteoblasts in the fracture gap may result in delayed healing. Furthermore, although certain amounts of fibrous tissue formation through fibroblast differentiation can stiffen the fracture callus, and so stabilize the fracture site $[45,9]$, too much fibrous tissue formation, resulting from excessive strain and interstitial fluid flow may result in delayed healing or non-union [45].

It can be seen from Fig.6 that a small fracture gap size (e.g. 1mm) under relatively flexible configurations of locking plate fixation could lead to excessive strain and fluid flow within the fracture site resulting in excessive fibrous tissue differentiation and delayed healing. By contrast, a relatively flexible configuration of locking plate fixation seems to benefit fracture healing under a relatively large gap size (e.g. $3 \mathrm{~mm}$ ). The computational simulation results are consistent with the study of Perren [8], which shows that cells within a small fracture gap experience larger strain than those within a large fracture gap. Clinical studies indicate that a very small fracture gap experiences very large strain and consequently 
delayed healing or non-union [11]. Consistent with clinical data [11,48], our computational simulation results suggest that a successful indirect healing is achievable when: (1) a relatively flexible fixation is applied on the fracture and (2) a relatively large fracture gap (i.e. 2-3 $\mathrm{mm}$ ) is left after fracture reduction. The computational simulation results suggest a correlation between fracture gap size and flexibility of locking plate fixation, indicating that a relatively flexible configuration of locking plate fixation is favourable for a relatively larger fracture gap. The results suggest that there should be an optimal fracture gap size and configuration of locking plate fixation for better healing outcomes. For example, chondroblast differentiation could happen at both the near and far cortex of the fracture with $3 \mathrm{~mm}$ gap size stabilized by $4.5 \mathrm{~mm}$ broad LCP with $\mathrm{WL}=65 \mathrm{~mm}$ and $\mathrm{BPD}=2 \mathrm{~mm}$. Studies show that the differentiation of chondroblast in the early stage of healing encourages cartilage tissue formation, which promotes indirect bone union [45].

\section{Limitations}

The current study has some limitations. For example, an axial compressive load of $100 \mathrm{~N}$ $200 \mathrm{~N}$ was applied on the proximal end of the fractured tibia (i.e. knee joint load). This loading condition represents the allowable partial weight bearing following surgical operation in the early stage of healing [30]. To simplify the complex problem, the muscle loadings were not included in the mechanical testing and the computational model, and only the effect of knee joint loading as the largest load applied on the bone during walking [28] were considered. In addition, the computational model results need to be further validated by animal experiments and clinical studies before it can be implemented for the development of patient-specific surgical treatment strategies. Moreover, it should be mentioned that the influence of patient age and genetic factors were not specifically included in this study.

\section{CONCLUSION}


In this study, we investigated the effect of the flexibility of locking plate fixation on callus mesenchymal stem cell differentiation in the early stage of fracture healing using mechanical testing in conjunction with computational modelling. The mechanical testing results suggest that the IFM at the near cortex of the fractures under rigid configurations of locking plate fixation can be too small to promote callus formation and bone healing. The results of the computational model suggest that the early-stage mesenchymal stem cell differentiation is highly influenced by the fracture gap size and locking plate fixation configuration.

Our simulation results indicated that the combination of gap size and fixation configuration has to be carefully chosen for fracture healing treatment. For example, under a small gap size (e.g. $1 \mathrm{~mm})$, a relatively flexible fixation configuration (e.g. $\mathrm{BPD}=2 \mathrm{~mm}$ and $\mathrm{WL}=65 \mathrm{~mm}$ ) could lead to excessive stress and strain at fracture site, whereas the same configuration would benefit callus formation through endochondral bone formation under a large gap size (i.e. $3 \mathrm{~mm}$ ). The developed model will allow orthopaedic surgeons to design patient-specific surgical solutions by establishing a rigorous scientific relationship between the configuration of the fixation system and the biological processes of healing, and thereby achieve optimal fracture healing outcomes.

\section{ACKNOWLEDGEMENTS}

352 The authors would like to thank AOTRAUMA Asia Pacific (AOTAP14-02), DePuy Synthes, of Melbourne for their support.

\section{REFERENCES}


358 1. Pape H-C, Bottlang M (2011) Flexible fixation with locking plates. J Orthop Trauma

359

360

361

362

363

364

365

366

367

368

369

370

371

372

373

374

375

376

377

378

379

380

381

382

383

384

385

386

387

388 25:S1-S3

2. Wu J-J, Shyr H, Chao E, Kelly P (1984) Comparison of osteotomy healing under external fixation devices with different stiffness characteristics. J Bone Joint Surg Am 66 (8):12581264

3. Goodship AE, Kenwright J (1985) The Influence of Induced Micromovement Upon the Healing of Experimental Tibial Fractures. J Bone Joint Surg Br 67 (4):650-655

4. Claes L, Augat P, Suger G, Wilke HJ (1997) Influence of size and stability of the osteotomy gap on the success of fracture healing. J Orthop Res 15 (4):577-584

5. Claes LE, Wilke HJ, Augat P, Rubenacker S, Margevicius KJ (1995) Effect of dynamization on gap healing of diaphyseal fractures under external fixation. Clin Biomech (Bristol, Avon) 10 (5):227-234

6. Bottlang M, Feist F (2011) Biomechanics of far cortical locking. J Orthop Trauma 25 (Suppl 1):S21

7. Augat P, Simon U, Liedert A, Claes L (2005) Mechanics and mechano-biology of fracture healing in normal and osteoporotic bone. Osteoporos Int 16 (2):S36-S43

8. Perren S (1979) Physical and biological aspects of fracture healing with special reference to internal fixation. Clin Orthop Relat Res 138:175-196

9. Claes L (2011) Biomechanical principles and mechanobiologic aspects of flexible and locked plating. J Orthop Trauma 25:S4-S7

10. Haidukewych GJ, Ricci W (2008) Locked plating in orthopaedic trauma: a clinical update. J Am Acad Orthop Surg 16 (6):347-355

11. Perren SM (2002) Evolution of the internal fixation of long bone fractures. The scientific basis of biological internal fixation: choosing a new balance between stability and biology. J Bone Joint Surg Br 84 (8):1093-1110

12. Egol KA, Kubiak EN, Fulkerson E, Kummer FJ, Koval KJ (2004) Biomechanics of locked plates and screws. J Orthop Trauma 18 (8):488-493

13. Kubiak EN, Fulkerson E, Strauss E, Egol KA (2006) The evolution of locked plates. J Bone Joint Surg Am 88 Suppl 4 (suppl_4):189-200. doi:10.2106/JBJS.F.00703

14. Strauss EJ, Schwarzkopf R, Kummer F, Egol KA (2008) The current status of locked plating: the good, the bad, and the ugly. J Orthop Trauma 22 (7):479-486 
15. Henderson CE, Bottlang M, Marsh JL, Fitzpatrick DC, Madey SM (2008) Does locked plating of periprosthetic supracondylar femur fractures promote bone healing by callus formation? Two cases with opposite outcomes. The Iowa orthopaedic journal 28:73 16. Lujan TJ, Henderson CE, Madey SM, Fitzpatrick DC, Marsh JL, Bottlang M (2010) Locked plating of distal femur fractures leads to inconsistent and asymmetric callus formation. J Orthop Trauma 24 (3):156-162

17. Miramini S, Zhang L, Richardson M, Pirpiris M, Mendis P, Oloyede K, Edwards G (2015) Computational simulation of the early stage of bone healing under different Locking Compression Plate configurations. Computer Methods in Biomechanics and Biomedical Engineering 18 (8):900-913

18. Miramini S, Zhang LH, Richardson M, Mendis P Computational Simulation of Mechanical Microenvironment of Early Stage of Bone Healing under Locking Compression Plate with Dynamic Locking Screws. In: Applied Mechanics and Materials, 2014. Trans Tech Publ, pp 281-286

19. Zhang ${ }^{1}$ L, Miramini S, Mendis P, Richardson M, Pirpiris M, Oloyede K (2013) The effects of flexible fixation on early stage bone fracture healing. International Journal of Aerospace and Lightweight Structures 3 (2):181-189

20. Thompson Z, Miclau T, Hu D, Helms JA (2002) A model for intramembranous ossification during fracture healing. J Orthop Res 20 (5):1091-1098

21. Klein P, Schell H, Streitparth F, Heller M, Kassi JP, Kandziora F, Bragulla H, Haas NP, Duda GN (2003) The initial phase of fracture healing is specifically sensitive to mechanical conditions. J Orthop Res 21 (4):662-669

22. Le A, Miclau T, Hu D, Helms J (2001) Molecular aspects of healing in stabilized and non-stabilized fractures. J Orthop Res 19 (1):78-84

23. Epari DR, Taylor WR, Heller MO, Duda GN (2006) Mechanical conditions in the initial phase of bone healing. Clin Biomech (Bristol, Avon) 21 (6):646-655. doi:10.1016/j.clinbiomech.2006.01.003

24. Kenwright J, Goodship AE (1989) Controlled mechanical stimulation in the treatment of tibial fractures. Clin Orthop Relat Res 241:36-47

25. Goodship AE, Cunningham JL, Kenwright J (1998) Strain rate and timing of stimulation in mechanical modulation of fracture healing. Clin Orthop Relat Res 355:S105-S115

26. Augat P, Margevicius K, Simon J, Wolf S, Suger G, Claes L (1998) Local tissue properties in bone healing: influence of size and stability of the osteotomy gap. J Orthop Res $16(4): 475-481$ 
27. Gautier E, Sommer C (2003) Guidelines for the clinical application of the LCP. Injury $34: 63-76$

28. Duda GN, Mandruzzato F, Heller M, Kassi JP, Khodadadyan C, Haas NP (2002) Mechanical conditions in the internal stabilization of proximal tibial defects. Clin Biomech (Bristol, Avon) 17 (1):64-72

29. Bottlang M, Doornink J, Fitzpatrick DC, Madey SM (2009) Far Cortical Locking Can Reduce Stiffness of Locked Plating Constructs While Retaining Construct Strength. J Bone Joint Surg Am 91a (8):1985-1994. doi:10.2106/Jbjs.H.01038

30. Döbele S, Horn C, Eichhorn S, Buchholtz A, Lenich A, Burgkart R, Nüssler AK, Lucke M, Andermatt D, Koch R (2010) The dynamic locking screw (DLS) can increase interfragmentary motion on the near cortex of locked plating constructs by reducing the axial stiffness. Langenbeck's Archives of Surgery 395 (4):421-428

31. Amano R, Sundén B (2011) Computational fluid dynamics and heat transfer: emerging topics, vol 23. WIT Press,

32. Fazi G, Tellini S, Vangi D, Branchi R (2010) Three-dimensional finite element analysis of different implant configurations for a mandibular fixed prosthesis. The International journal of oral \& maxillofacial implants 26 (4):752-759

33. Cepeda J, Birla S, Subbiah J, Thippareddi H A Practical Method to Model Complex Three-Dimensional Geometries with Non-Uniform Material Properties Using Image-based Design and COMSOL Multiphysics®. In: COMSOL Conference, Boston, 2013. 34. Mimics (2011). vol 14.11. Materialise, Haasrode, Belgium

35. Horn C, Doebele S, Vester H, Schaeffler A, Lucke M, Stoeckle U (2011) Combination of interfragmentary screws and locking plates in distal meta-diaphyseal fractures of the tibia: a retrospective, single-centre pilot study. Injury 42 (10):1031-1037

36. Biot MA (2004) General theory of three-dimensional consolidation. Journal of applied physics $12(2): 155-164$

37. Terzaghi K (1943) Theoretical soil mechanics. J. Wiley, New York

38. Oloyede A, Broom N (1991) Is classical consolidation theory applicable to articular cartilage deformation? Clinical Biomechanics 6 (4):206-212

39. Mow V, Kuei S, Lai W, Armstrong C (1980) Biphasic creep and stress relaxation of articular cartilage in compression: theory and experiments. J Biomech Eng 102 (1):73-84 40. Zhang L, Miramini S, Smith DW, Gardiner BS, Grodzinsky AJ (2014) Time Evolution of Deformation in a Human Cartilage Under Cyclic Loading. Ann Biomed Eng:1-12 
456 41. Lacroix D, Prendergast P (2002) A mechano-regulation model for tissue differentiation 457 during fracture healing: analysis of gap size and loading. J Biomech 35 (9):1163-1171

458 42. Prendergast P, Huiskes R, Søballe K (1997) Biophysical stimuli on cells during tissue 459 differentiation at implant interfaces. J Biomech 30 (6):539-548

460 43. Huiskes R, Van Driel W, Prendergast P, Søballe K (1997) A biomechanical regulatory 461 model for periprosthetic fibrous-tissue differentiation. J Mater Sci Mater Med 8 (12):785-788 462 44. Isaksson $\mathrm{H}$, van Donkelaar CC, Huiskes $\mathrm{R}$, Ito $\mathrm{K}$ (2006) Corroboration of 463 mechanoregulatory algorithms for tissue differentiation during fracture healing: comparison 464 with in vivo results. J Orthop Res 24 (5):898-907

465 45. Claes L, Reusch M, Göckelmann M, Ohnmacht M, Wehner T, Amling M, Beil FT, 466 Ignatius A (2011) Metaphyseal fracture healing follows similar biomechanical rules as 467 diaphyseal healing. J Orthop Res 29 (3):425-432

468 46. Woo S, Lothringer K, Akeson W, Coutts R, Woo Y, Simon B, Gomez M (1983) Less 469 rigid internal fixation plates: historical perspectives and new concepts. J Orthop Res 1 470 (4):431-449

471 47. McKibbin B (1978) The biology of fracture healing in long bones. J Bone Joint Surg Br $472 \quad 60-\mathrm{B}(2): 150-162$

473 48. Perren SM (2008) Fracture healing. The evolution of our understanding. Acta Chir 474 Orthop Traumatol Cech 75 (4):241

475 49. McCartney W, Mac Donald BJ, Hashmi MSJ (2005) Comparative performance of a 476 flexible fixation implant to a rigid implant in static and repetitive incremental loading. 477 Journal of Materials Processing Technology $169 \quad$ (3):476-484. 478 doi:10.1016/j.jmatprotec.2005.04.104 
Tables:

483

484 Table 1 Configurations of locking plate fixation used in the mechanical testing

\begin{tabular}{cccc}
\hline Configuration & $\begin{array}{c}\text { Number of surrogate } \\
\text { specimens }\end{array}$ & $\begin{array}{c}\text { Bone-plate distance } \\
\text { (BPD) }\end{array}$ & $\begin{array}{c}\text { Working length } \\
\text { (WL) }\end{array}$ \\
\hline C1 (control) & 5 & $2 \mathrm{~mm}$ & $30 \mathrm{~mm}$ \\
C2 & 5 & $4 \mathrm{~mm}$ & $30 \mathrm{~mm}$ \\
C3 & 5 & $2 \mathrm{~mm}$ & $100 \mathrm{~mm}$ \\
C4 & 5 & $4 \mathrm{~mm}$ & $100 \mathrm{~mm}$ \\
\hline
\end{tabular}

485

486

487 Table 2 Material properties of tissues used in this study, ${ }^{\mathrm{a}}$ McCartney et al. [49], ${ }^{\mathrm{b}}$ Lacroix, 488 Prendergast [41]

\begin{tabular}{lccc}
\hline Parameter & Granulation tissue & Marrow & Cortical bone \\
\hline Young's modulus (MPa) & $0.05^{\mathrm{a}}$ & $2^{\mathrm{b}}$ & $20000^{\mathrm{b}}$ \\
Poisson's Ratio & $0.17^{\mathrm{b}}$ & $0.17^{\mathrm{b}}$ & $0.3^{\mathrm{b}}$ \\
Porosity & $0.8^{\mathrm{b}}$ & $0.8^{\mathrm{b}}$ & $0.04^{\mathrm{b}}$ \\
Permeability (m $\left.\mathrm{m}^{4} / \mathrm{Ns}\right)$ & $10^{-14} \mathrm{~b}$ & $10^{-14} \mathrm{~b}$ & $10^{-17} \mathrm{~b}$ \\
Fluid compression modulus (MPa) & $2300^{\mathrm{b}}$ & $2300^{\mathrm{b}}$ & $2300^{\mathrm{b}}$ \\
Solid compression modulus (MPa) & $2300^{\mathrm{b}}$ & $2300^{\mathrm{b}}$ & $13920^{\mathrm{b}}$ \\
\hline 89
\end{tabular}

490

491 Table 3 Percent increase of IFM relative to control $(\mathrm{C} 1,100 \mathrm{~N})$ for different configurations of

492 locking plate fixation and load magnitudes

493

\begin{tabular}{|c|c|c|c|c|c|c|}
\hline \multirow{3}{*}{ Configuration } & \multicolumn{6}{|c|}{ Percent increase of IFM relative to control $(\mathrm{C} 1,100 \mathrm{~N})$} \\
\hline & \multicolumn{3}{|c|}{ Near cortex } & \multicolumn{3}{|c|}{ Far cortex } \\
\hline & $100 \mathrm{~N}$ & $150 \mathrm{~N}$ & $200 \mathrm{~N}$ & $100 \mathrm{~N}$ & $150 \mathrm{~N}$ & $200 \mathrm{~N}$ \\
\hline $\mathrm{C} 1$ & control & $\begin{array}{c}40 \% \\
(p<0.05)\end{array}$ & $\begin{array}{c}119 \% \\
(p<0.05)\end{array}$ & control & $\begin{array}{c}26 \% \\
(p<0.05)\end{array}$ & $\begin{array}{c}82 \% \\
(p<0.05)\end{array}$ \\
\hline $\mathrm{C} 2$ & $\begin{array}{c}46 \% \\
(p<0.05)\end{array}$ & $\begin{array}{c}148 \% \\
(p<0.05)\end{array}$ & $\begin{array}{c}255 \% \\
(p<0.05)\end{array}$ & $\begin{array}{c}\text { No } \\
\text { significant } \\
\text { increase } \\
(p=0.07)\end{array}$ & $\begin{array}{c}53 \% \\
(p<0.05)\end{array}$ & $\begin{array}{c}113 \% \\
(p<0.05)\end{array}$ \\
\hline $\mathrm{C} 3$ & $\begin{array}{c}130 \% \\
(p<0.05)\end{array}$ & $\begin{array}{c}305 \% \\
(p<0.05)\end{array}$ & $\begin{array}{c}438 \% \\
(p<0.05)\end{array}$ & $\begin{array}{c}38 \% \\
(p<0.05)\end{array}$ & $\begin{array}{c}130 \% \\
(p<0.05)\end{array}$ & $\begin{array}{c}200 \% \\
(p<0.05)\end{array}$ \\
\hline $\mathrm{C} 4$ & $\begin{array}{c}218 \% \\
(p<0.05)\end{array}$ & $\begin{array}{c}412 \% \\
(p<0.05)\end{array}$ & $\begin{array}{c}668 \% \\
(p<0.05)\end{array}$ & $\begin{array}{c}80 \% \\
(p<0.05)\end{array}$ & $\begin{array}{c}169 \% \\
(p<0.05)\end{array}$ & $\begin{array}{c}295 \% \\
(p<0.05)\end{array}$ \\
\hline
\end{tabular}


495 Table 4 Percent decrease of $\mathrm{IFM}_{\mathrm{FC}} / \mathrm{IFM}_{\mathrm{NC}}$ relative to control $(\mathrm{C} 1,100 \mathrm{~N})$ for different 496 configurations of locking plate fixation and load magnitudes

\begin{tabular}{cccc}
\hline \multirow{2}{*}{ Configuration } & \multicolumn{3}{c}{ Percent decrease of $\mathrm{IFM}_{\mathrm{FC}} / \mathrm{IFM}_{\mathrm{NC}}$ relative to control $(\mathrm{C} 1,100 \mathrm{~N})$} \\
\cline { 2 - 4 } C1 & $100 \mathrm{~N}$ & $150 \mathrm{~N}$ & $200 \mathrm{~N}$ \\
\hline $\mathrm{C} 2$ & $10 \%(p<0.05)$ & $15 \%(p<0.05)$ & $18 \%(p<0.05)$ \\
\hline $\mathrm{C} 3$ & $21 \%(p<0.05)$ & $23 \%(p<0.05)$ & $\begin{array}{c}\text { No significant } \\
\text { decrease } \\
(p=0.07)\end{array}$ \\
\hline $\mathrm{C} 4$ & $23 \%(p<0.05)$ & $24 \%(p<0.05)$ & $25 \%(p<0.05)$ \\
\hline
\end{tabular}

497

498 


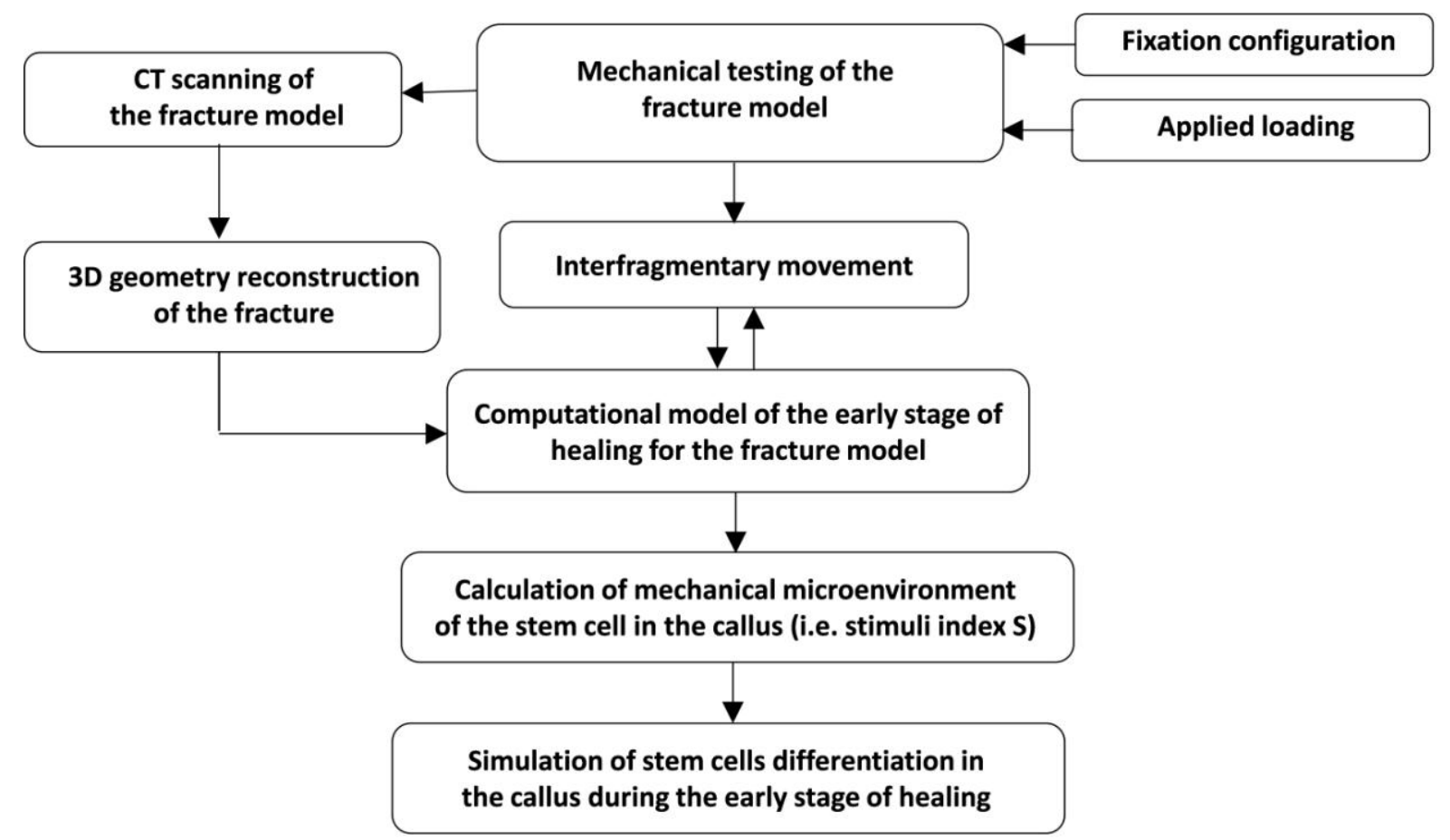

500 Fig.1 Schematic diagram illustrates methodology of this study

(a)



(b)

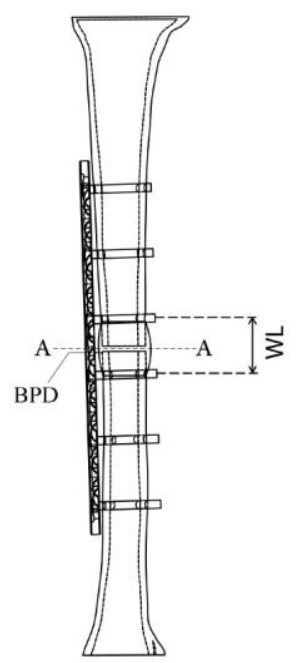

(c)



Fig.2 (a) Mechanical testing system used in this study (Instron 5569A; Instron, Canton, Massachusetts). (b) Bone fracture model geometry indicating working length (WL), boneplate distance (BPD). (c) Finite element model of tibia fracture with the incorporation of

507 facture callus 

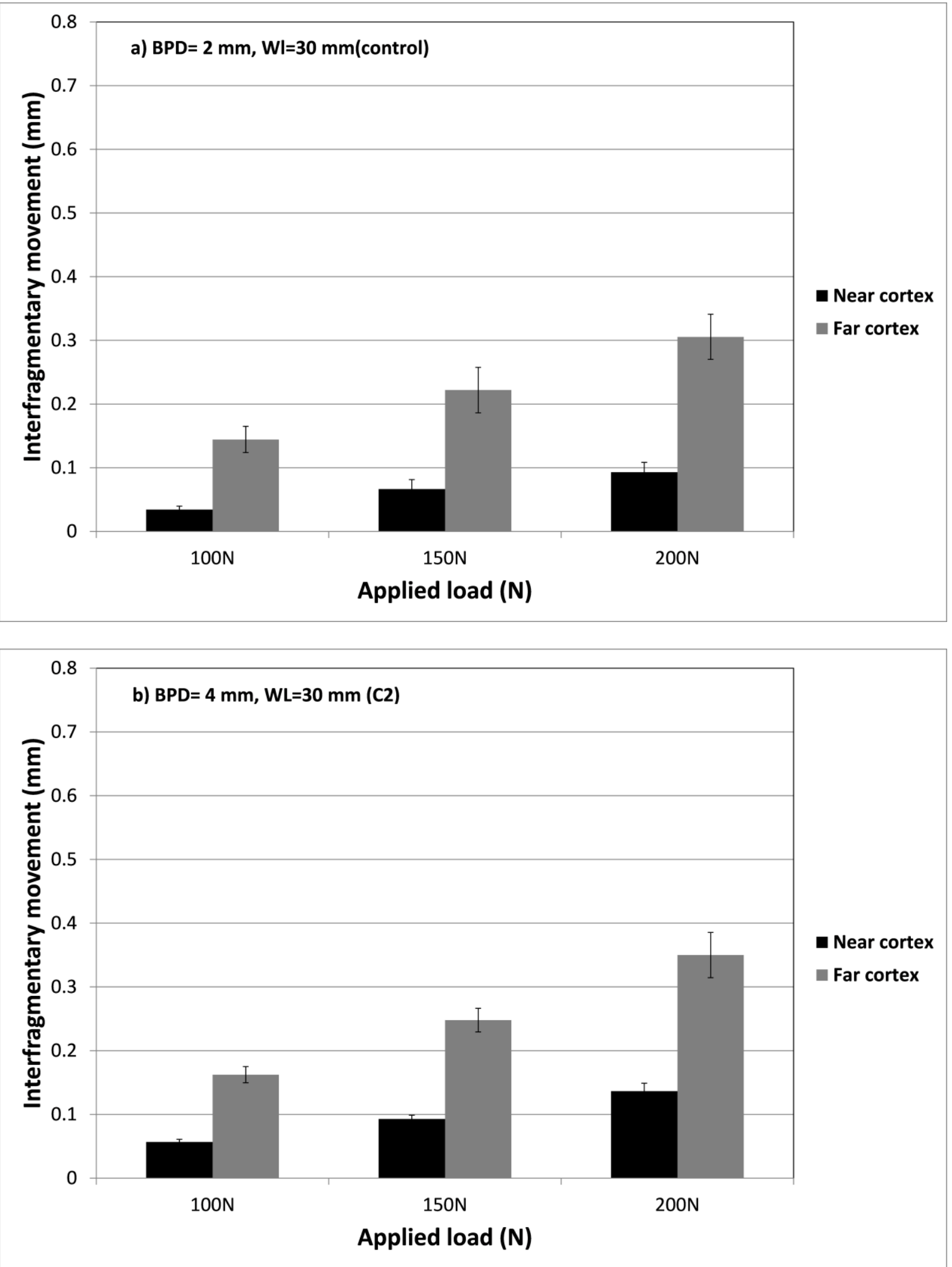



$512 \quad$ Fig.3 The experimental measurements for IFM at the near and far cortex of the fractures 513 stabilized by different configurations of locking plate fixation: (a) $B P D=2 \mathrm{~mm}, \mathrm{WL}=30 \mathrm{~mm}$ 514 (control), (b) BPD=4 mm, WL=30 mm (C2), (c) BPD=2 mm, WL=100 mm (C3) and (d) $515 \mathrm{BPD}=4 \mathrm{~mm}, \mathrm{WL}=100 \mathrm{~mm}(\mathrm{C} 4)$ 




Fig.4 The ratio of IFM at far cortex $\left(I F M_{F C}\right)$ to IFM at near cortex $\left(I F M_{N C}\right)$ for different configurations of locking plate fixation

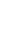

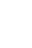


(a)

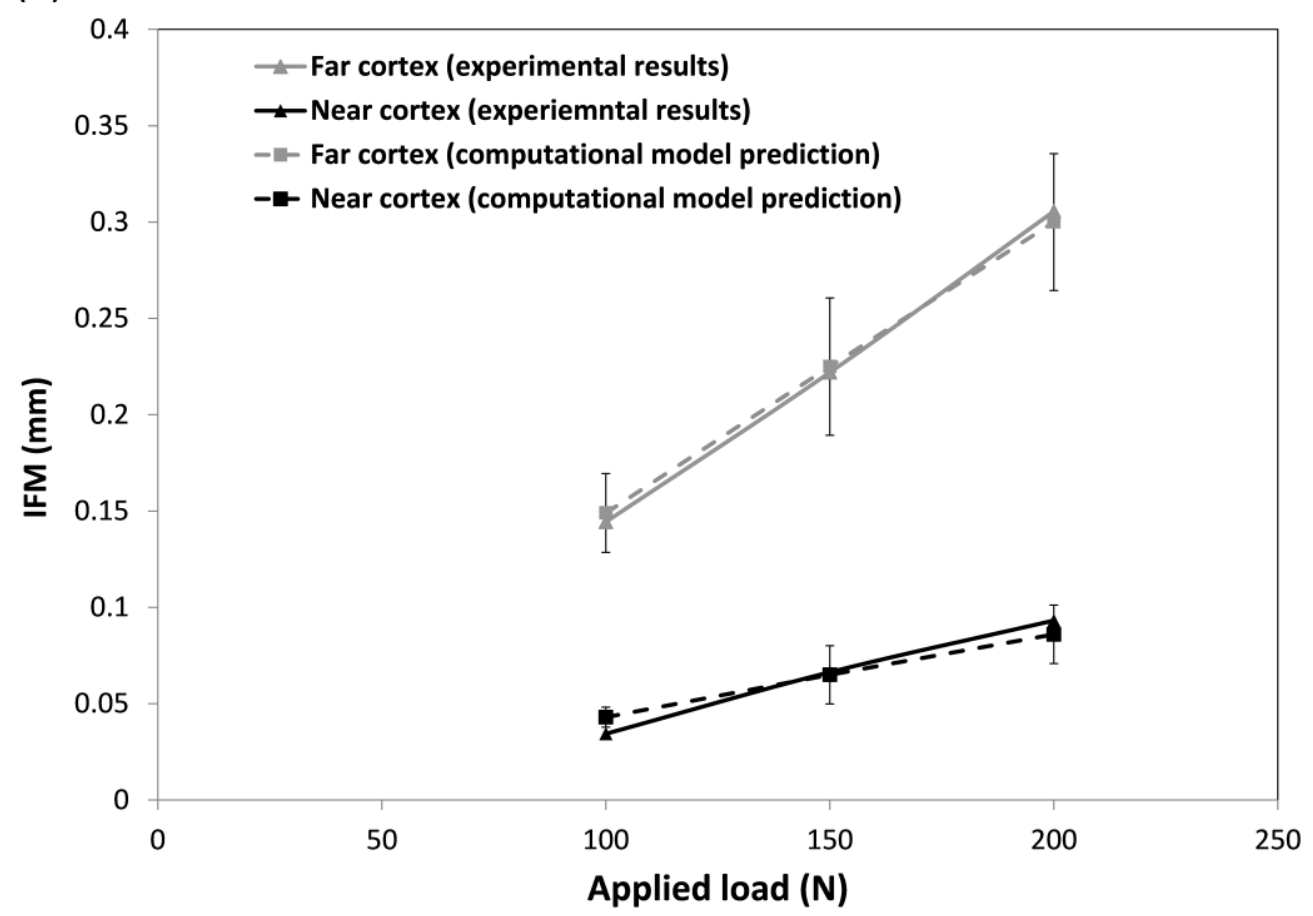

(b)

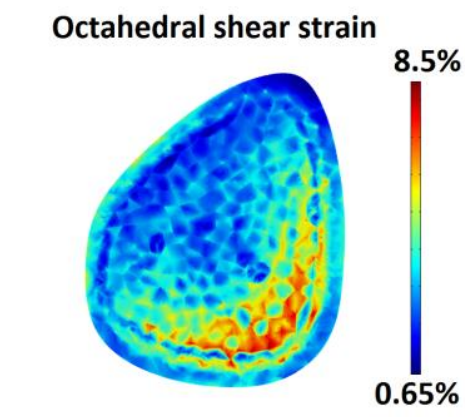

Interstitial fluid flow (m/s)

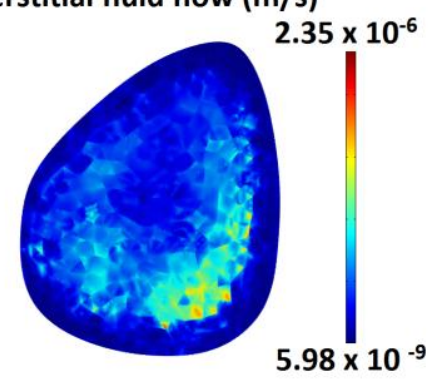

Cell differentiation pattern

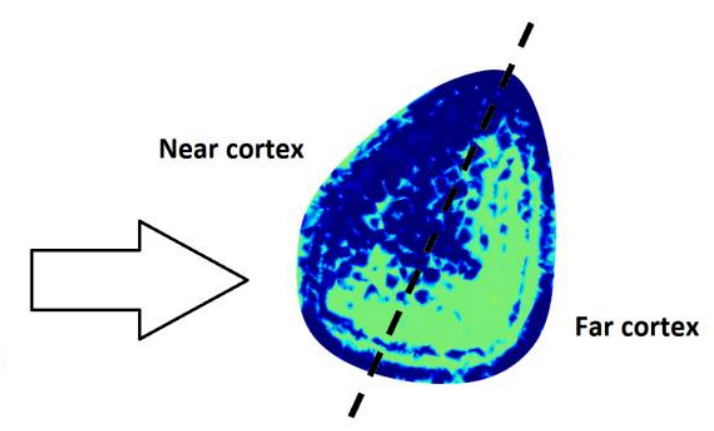

Osteoblast differentiation

Chondroblast differentiation

Fibroblast differentiation

535 Fig.5 (a) Comparison of the computational model result with that from the experimental 536 measurements $(\mathrm{C} 1$, control). (b) Computational model prediction of cell differentiation at 537 transverse cross-section of the callus during the early stage of healing depending on octahedral shear strain and interstitial fluid flow of the granulation tissue $(\mathrm{C} 1,150 \mathrm{~N}$, gap 539 size $=3 \mathrm{~mm}$ ) 
Fracture gap size $=1 \mathrm{~mm}$

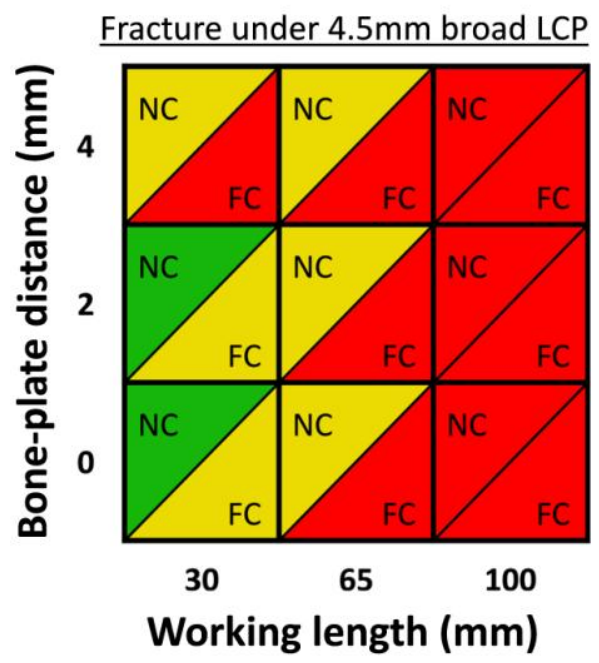

Fracture gap size $=3 \mathrm{~mm}$

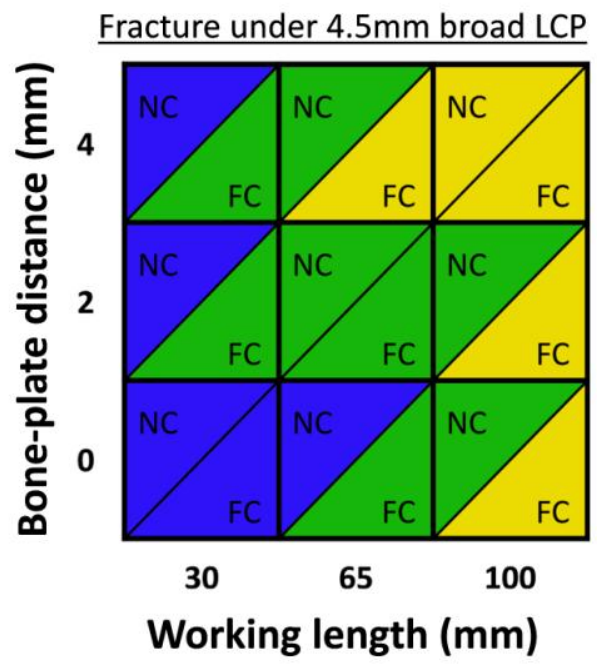

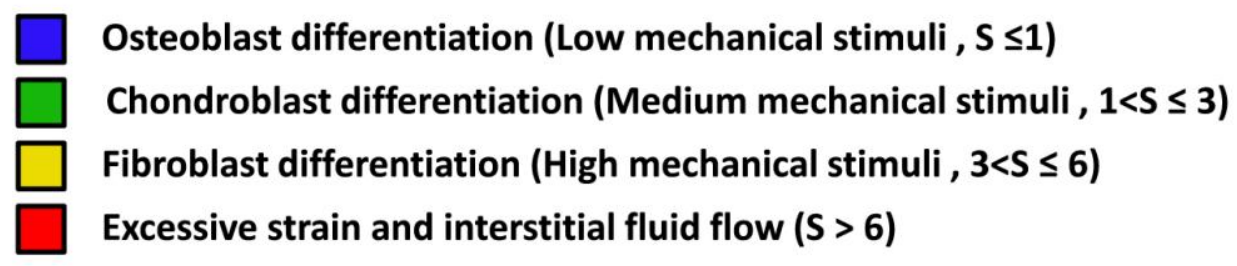

541 Fig.6 The average mechanical stimuli index (S) and dominant cell differentiation during the 542 early stage of healing, at near cortex (NC) and far cortex (FC) for the fractures with $1 \mathrm{~mm}$ and $5433 \mathrm{~mm}$ gap size respectively stabilized by $4.5 \mathrm{~mm}$ broad locking plate fixation 